\title{
Experimental and Analytical Studies of Door-Type Modular Scaffolds with Initial Geometrical Imperfections
}

\author{
Piya Chotickai ${ }^{\mathrm{a}, *}$ and Sitthinon Kaewsawang ${ }^{\mathrm{b}}$ \\ Department of Civil Engineering, Faculty of Engineering, Kasetsart University \\ 50 Ngam Wong Wan Rd., Lat Yao, Chatuchak, Bangkok, 10900, Thailand \\ E-mail: afengpyc@ku.ac.th (Corresponding author), bsitthinon.ka@ku.th
}

\begin{abstract}
In the study, the performance and structural behaviors of door-type modular steel scaffolds with different degrees of initial geometrical imperfections were evaluated through experimental and analytical investigations. Two one-story and nine two-story modular steel scaffolds were tested to failure with a minimum extension of the screw jacks at the base and the u-heads at the top. The initial out-of-straightness along the column height $(\mathrm{H})$ and the initial out-of-plumbness were measured. When the number of stories increased from 1 to 2 , a $14.8 \%$ reduction in load capacity was obtained for the scaffolds with the initial out-ofstraightness in a range of $\mathrm{H} / 1889$ to $\mathrm{H} / 1318$. The capacity reduction was mainly due to flexibility at column joints and an increase in the deviation from the vertical alignment. With respect to the out-of-plumbness ratio in a range of $\mathrm{H} / 149$ to $\mathrm{H} / 119$, the average capacity reductions increased to $18.9 \%$ and $20.9 \%$ when the out-of-straightness approached and exceeded the limit $(\mathrm{H} / 1000)$ specified in the standards. The effective length factors and the effects of boundary and continuity conditions on the ultimate load were determined. In conjunction with the initial imperfections, the results indicated that the flexibility at column joints and the stiffness of beam and sub-frame elements on modular frames significantly affected the failure mode and ultimate load. The beam and sub-frame elements prevented the buckling failure in the modular-frame plane. Hence, the initial imperfections in the plane of cross bracings were more critical than that of the modular-frame plane, and it is necessary to closely inspect the same while using scaffolds in construction.
\end{abstract}

Keywords: Buckling, geometrical imperfection, modular scaffold, steel.

ENGINEERING JOURNAL Volume 22 Issue 6

Received 19 April 2018

Accepted 23 August 2018

Published 4 December 2018

Online at http://www.engj.org/

DOI:10.4186/ej.2018.22.6.135 


\section{Introduction}

Door-type modular steel scaffolds are widely used to temporarily support fresh concrete and other temporary loads. Modular scaffolds are commonly used as a supporting structure in construction because they are easy to install and dismantle. The applied load on scaffolds can be relatively accurately estimated when compared with loads on permanent structures that display a significantly longer service life. However, the scaffolds often fail during construction and lead to damage, injuries, and work delays. A high incident rate of scaffold failure is reported [1,2]. The failures were identified as due to inadequate design, improper site supervision, and overload.

The scaffold members are composed of slender members with high strength steel tubes. The scaffolding frames are linked-up with diagonal bracings. The continuity between story levels is provided by a joint pin connection. The relatively slender members of the scaffolds are susceptible to local and global elastic instability [3]. The scaffolds can buckle in both the in-plane and out-of-plane of scaffold frames based on steel grades, scaffolding geometries, and boundary conditions [4].

The steel modular scaffolds are commonly reused in construction and result in a high variation in geometric properties of scaffold members [5]. The scaffolds can contain initial imperfections including the loss of sectional area due to corrosion, member out-of-straightness, and deviation from vertical alignment or out-of-plumbness owing to handling and reusable applications. This increases the potential risk of scaffolding failure.

Several studies investigated the load capacity of modular steel scaffolds using experimental and analytical approaches [6-9]. The load carrying capacity of modular scaffolds was reported to depend on several parameters including joint stiffness, boundary conditions, initial imperfections, and the presence of diagonal bracing. Peng et al. [10] evaluated the performance of door-shaped steel scaffolds with an inner reinforced gable sub-frame by using experimental and analytical investigations. The notional lateral load analysis indicated that the initial out-of-plumbness of $1.5 \%$ leaded to a $15.6 \%$ reduction in the ultimate load. The effects of load eccentricity and boundary condition on the load capacity of the similar type of scaffolds with several stories ranging from 2 to 12 were numerically investigated by Peng et al. [11]. The eccentricity was reported to cause a significant reduction on the ultimate load. The fixed base increased the load capacity of scaffolds when compared with that of hinged-base condition. The difference between the critical loads provided by the two boundary conditions gradually decreased with an increase in the number of scaffolding stories. Yu et al. [4] investigated the influence of initial geometrical imperfections in modular steel scaffolds by using three different numerical approaches, namely the notional load approach, eigenmode imperfection approach, and critical load approach according to BS 5950 [12]. The lateral loads were applied at each story level to include initial imperfections in the notional load approach. The eigenmode imperfection approach assigned initial geometrical imperfections based on the lowest eigenvalue. The eigenmode imperfection approach tended to provide conservative and economical results. Peng et al. [13] investigated the effect of the initial defect on the performance of single-row steel scaffolds. To simulate the worst condition of reused scaffolds, the second load was applied on the scaffolds after the first maximum load. A reduction in the load capacity in the range of $11 \%$ to $30 \%$ was obtained from the scaffolds with the initial defect caused by the first maximum load. Although several studies evaluated the effects of initial geometrical imperfections on the load capacity of modular steel scaffolds, limited experimental and analytical investigations investigated the door-type modular scaffolds with initial geometrical imperfections corresponding to the reused scaffolds in the construction. Given the lack of information, the actual performance of the scaffolds that are currently used could not be accurately estimated.

The primary objective of the study involved evaluating the performance of door-type modular scaffolds currently used in the construction. The scaffolds with different levels of initial geometrical imperfections were tested to failure. The effects of geometrical imperfections on the failure mode, failure mechanisms, utilization of member strength, and effective length factor were examined. The effects of boundary conditions and flexibility at the column joints on the ultimate loads were evaluated by performing an analytical investigation.

\section{Experimental Program}

The experimental program comprised of the compression tests of two one-story and nine two-story doortype modular steel scaffolds with different degrees of initial geometrical imperfections. 


\subsection{Specimen Description and Dimensions}

The scaffolds were composed of vertical columns, diagonal bracings, and horizontal ledgers as shown in Fig. 1. The height of each modular frame was equal to $1,700 \mathrm{~mm}$. The diagonal bracings provided the cross link between two modular frames. The connection between columns at each story level was obtained by using joint pins. The scaffold height can be adjusted with jack base and u-head. The sub-frame elements on the modular frames provided access between the story levels. Table 1 lists the sectional properties of column, diagonal bracing, ledger, and sub-frame elements of the modular scaffolds. The dimensions of the jack base, u-head, and joint pin are shown in Fig. 1. For the purposes of easy reference, the directions along the plane of the modular frame and cross-bracing were referred to as the $\mathrm{X}$ and $\mathrm{Y}$ directions, respectively.
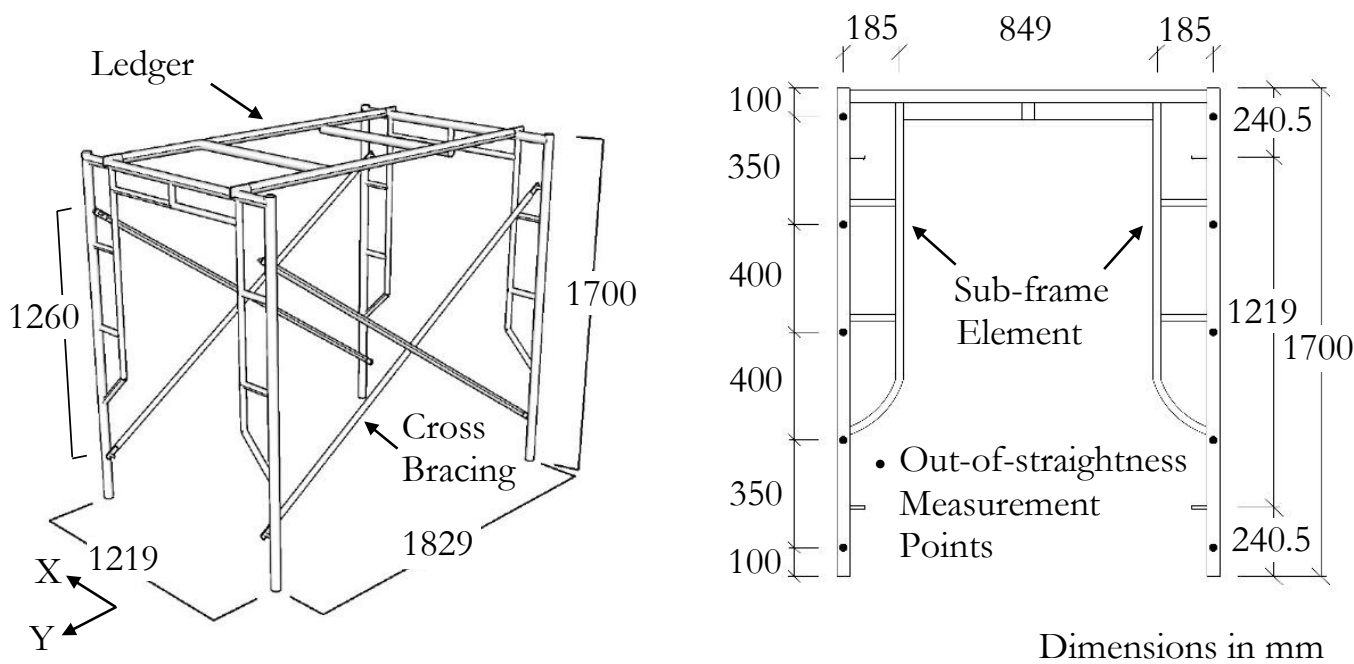

Dimensions in $\mathrm{mm}$

a) Dimension of the Door-Type Modular Scaffold

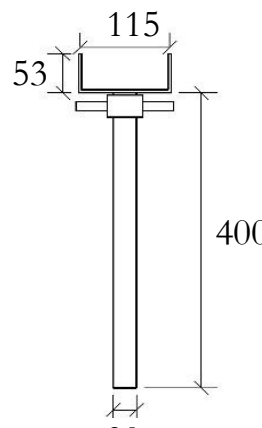

30

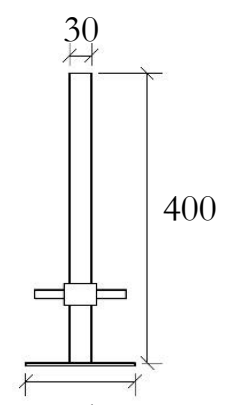

150

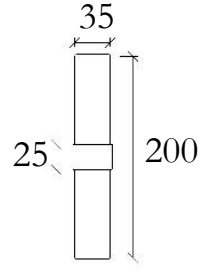

Dimensions in $\mathrm{mm}$

b) U-head

d) Joint Pin

Fig. 1. Dimension of the door-type modular scaffold and components.

Prior to the installation, the initial out-of-straightness of each column was measured at five locations along the height $(\mathrm{H})$, namely $100 \mathrm{~mm}$ and $450 \mathrm{~mm}$ from top and bottom and mid-height in both the $\mathrm{X}$ and $\mathrm{Y}$ directions. Three locations in the middle region were selected to measure the out-of-straightness of columns deformed in either single or double curvatures. A straight rigid bar with V-shaped supports was mounted at top and bottom of the columns. The rigid bar provided a reference line, as a dial gage was moved along the height of the column for the out-of-straightness measurement. The specimens were then grouped based on the existing initial geometrical conditions as shown in Table 2. The specimens with one and two stories are referred to as specimens S1 and S2, respectively. Based on the existing column straightness, the specimens were grouped into damage levels D0, D1, and D2. The damage levels D0, D1, and D2 represented new scaffolds with relatively straight columns, reused scaffolds with initial out-of-straightness in both the $\mathrm{X}$ and $\mathrm{Y}$ directions less than the limit of $\mathrm{H} / 1000$ equal to $1.70 \mathrm{~mm}$, and scaffolds with out-of-straightness in either the $\mathrm{X}$ or $\mathrm{Y}$ directions that exceeded the limit, respectively. The initial out-of-straightness of specimens 
D0 was in a range of $\mathrm{H} / 1889$ to $\mathrm{H} / 1318$. The limit of the out-of-straightness of $\mathrm{H} / 1000$ corresponded to the requirement specified in the standards for steel structures (AS 4100 [14], AISC 303 [15]) and the code of practice of falsework (BS 5975 [16]).

Table 1. Sectional properties of members in door-type modular scaffolds.

\begin{tabular}{lllll}
\hline Element & $\begin{array}{l}\text { Outside } \\
\text { Diameter }(\mathbf{m m})\end{array}$ & $\begin{array}{l}\text { Thickness } \\
\mathbf{( m m})\end{array}$ & $\begin{array}{l}\text { Cross-sectional } \\
\text { Area }\left(\mathbf{m m}^{2}\right)\end{array}$ & $\begin{array}{l}\text { Moment of } \\
\text { Inertia }\left(\mathbf{m m}^{4}\right)\end{array}$ \\
\hline Column & 42.0 & 1.80 & 227 & 46,012 \\
Diagonal Bracing & 25.8 & 1.57 & 119 & 8,763 \\
Ledger & 41.6 & 1.79 & 223 & 44,472 \\
Sub-frame Element & 25.5 & 1.54 & 115 & 8,331 \\
\hline
\end{tabular}

Specimens S2D2-1 and S2D2-3 exhibited the maximum out-of-straightness in the Y direction (plane of cross bracing) corresponding to $2.16 \mathrm{~mm}$ and in the X direction (plane of modular frame) of $4.49 \mathrm{~mm}$, respectively. These corresponded to out-of-straightness ratios of H/787 and H/379. Figure 2 shows the outof-straightness measurement and the distributions of out-of-straightness in $\mathrm{X}$ and $\mathrm{Y}$ directions for specimens D0, D1, and D2. The out-of-straightness values at $450 \mathrm{~mm}$ from top and bottom and at mid-height are included in the distributions.

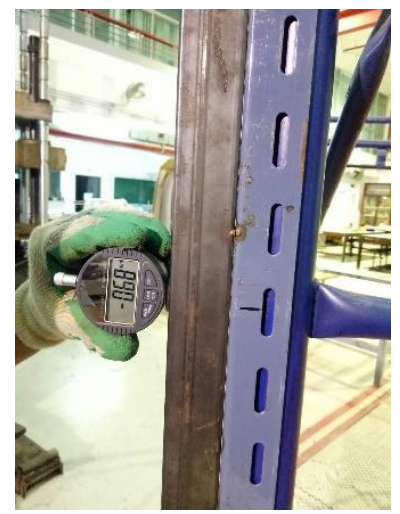

a) Out-of-Straightness Measurement

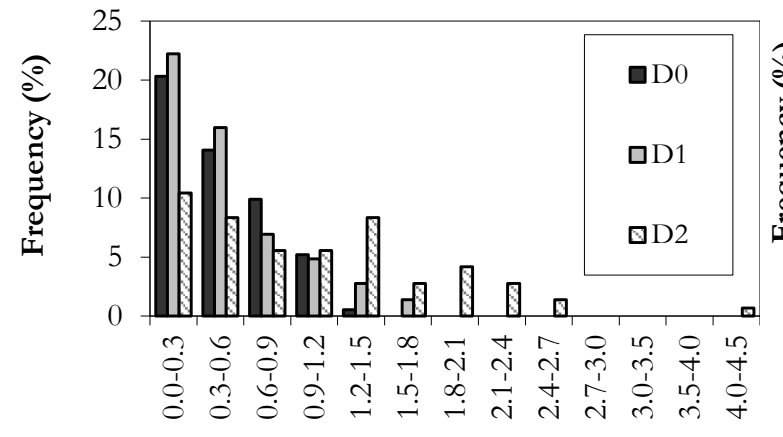

Out-of-Straightness (mm)

b) X Direction

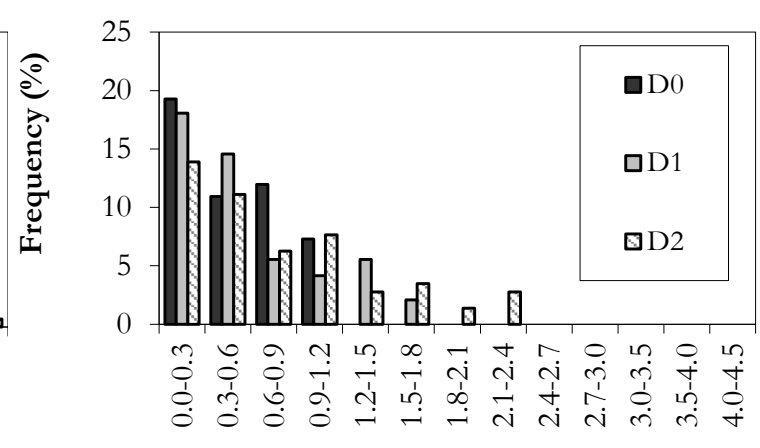

Out-of-Straightness (mm)

c) Y Direction

Fig. 2. Out-of-straightness measurement and distribution of out-of-straightness of columns.

The out-of-plumbness in $\mathrm{X}$ and $\mathrm{Y}$ directions at the top of each specimen were measured by using a theodolite. The magnitudes of out-of-plumbness at the top story of the specimens are listed in Table 2 . The limit on the out-of-plumbness varied among the standards in a range from H/100 to H/600. The AS 4100 and AISC 303 standards specified that the out-of-plumbness should not exceed H/500. Based on good practice guidelines, BS 5975 specified the maximum out-of-plumbness as less than $\mathrm{H} / 600$ with the maximum limit of $25 \mathrm{~mm}$. The code practice for the access scaffold (CSA Z797-09 [17]) provided the limit for the out- 
of-plumbness to not exceed $\mathrm{H} / 250$ for the 3 - $\mathrm{m}$ height and $\mathrm{H} / 315$ for the 6 - $\mathrm{m}$ height. The aforementioned requirements are less stringent when compared with AS 4100, AISC 303, and BS 5975. The code of practice for metal scaffolding safety [18] specified the out-of-plumbness as within $\mathrm{H} / 100$.

The maximum out-of-plumbness of specimens S1 was less than the limit of H/600. The story out-ofplumbness in X direction (plane of modular frame) for most of specimens S2 exceeded the limited value of $\mathrm{H} / 600$ or $5.67 \mathrm{~mm}$ for a height of $3.4 \mathrm{~m}$ although it was less than the maximum limit of $25 \mathrm{~mm}$. Only specimen S2D1-2 exhibited a maximum out-of-plumbness in X direction exceeding the limit of $25 \mathrm{~mm}$. The out-of-plumbness ratios in the Y direction (plane of cross bracing) for all specimens S2 exceeded the limit value of $\mathrm{H} / 600$. The specimens S2D0, S2D1, and S2D2 exhibited a variation in the out-of-plumbness in the $\mathrm{Y}$ direction in the same range as the average ratios corresponding to $\mathrm{H} / 119, \mathrm{H} / 149$, and $\mathrm{H} / 137$, respectively. The deviation from vertical alignment was due to the flexibility at the connections of modular frames.

To evaluate the actual thickness of columns with different initial imperfections, the ultrasonic pulse-echo contact measurement (ASTM E797 [19]) was used at the same locations of the out-of-straightness measurement. The average thickness of column in each specimen is listed in Table 2. The value was obtained from the average of 4 columns for one-story specimens and 8 columns for two-story specimens.

Table 2. Specimen details and initial geometrical imperfections.

\begin{tabular}{|c|c|c|c|c|c|c|}
\hline \multirow{2}{*}{$\begin{array}{l}\text { Specimen } \\
\text { No. }\end{array}$} & \multirow{2}{*}{$\begin{array}{l}\text { Number } \\
\text { of Stories }\end{array}$} & \multicolumn{2}{|c|}{$\begin{array}{l}\text { Maximum Out-of- } \\
\text { Straightness }(\mathrm{mm})\end{array}$} & \multicolumn{2}{|c|}{ Out-of-Plumbness (mm) } & \multirow{2}{*}{$\begin{array}{l}\text { Average } \\
\text { Thickness } \\
(\mathrm{mm})\end{array}$} \\
\hline & & X Direction & Y Direction & X Direction & Y Direction & \\
\hline S1D0-1 & 1 & 1.13 & 0.9 & 0.26 & 0.28 & 1.80 \\
\hline S1D0-2 & 1 & 1.00 & 1.08 & 0.09 & 1.42 & 1.80 \\
\hline S2D0-1 & 2 & 1.12 & 1.04 & 5.76 & 27.63 & 1.80 \\
\hline S2D0-2 & 2 & 1.29 & 1.13 & 19.49 & 35.65 & 1.77 \\
\hline S2D0-3 & 2 & 1.13 & 1.17 & 6.93 & 24.57 & 1.77 \\
\hline S2D1-1 & 2 & 1.21 & 1.56 & 8.39 & 25.21 & 1.78 \\
\hline S2D1-2 & 2 & 1.62 & 1.54 & 27.78 & 17.30 & 1.79 \\
\hline S2D1-3 & 2 & 1.28 & 1.43 & 14.11 & 29.41 & 1.77 \\
\hline S2D2-1 & 2 & 2.62 & 2.16 & 1.20 & 38.77 & 1.73 \\
\hline S2D2-2 & 2 & 1.88 & 1.75 & 4.78 & 18.79 & 1.75 \\
\hline S2D2-3 & 2 & 4.49 & 2.14 & 11.86 & 23.75 & 1.67 \\
\hline
\end{tabular}

\subsection{Mechanical Properties}

The mechanical properties, including the modulus of elasticity and yield strength, of columns were obtained from new modular frames (specimens D0). Three samples were subjected to tensile tests based on ASTM E8 [20]. The yield strength was obtained using the $0.2 \%$ offset method. The average modulus of elasticity and yield strength corresponded to $212,387 \mathrm{MPa}$ and $435 \mathrm{MPa}$, respectively.

A hardness nondestructive test was employed to evaluate a variation in the yield strength between specimens with different levels of initial geometrical imperfections. Hardness values exhibited a linear relationship with the strength of materials [21]. The hardness values were determined at the same locations as the out-of-straightness measurement by using a portable hardness tester. Figure 3 presents the histograms of Rockwell B hardness values obtained from the specimens. The variation in the hardness values was anticipated to be due to curved surface of the scaffolding columns. The average hardness values of specimens D0, D1, and D2 were observed as relatively close and equal to 57.5, 55.0, and 54.3, respectively. Therefore, a significant shift in the yield strength was not expected in the specimens with different initial geometrical imperfections used the study. 


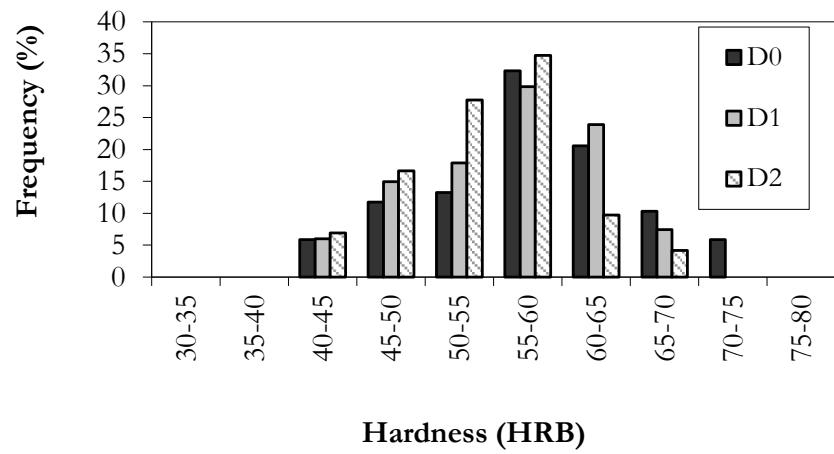

Fig. 3. Hardness values of columns.

\subsection{Experimental Setup}

The scaffold specimens were tested until failure occurred. The vertical load was applied by using hydraulic jack at the center point of the horizontal plane at the top of each specimen. The screw jacks at the base and $\mathrm{u}$-heads at the top were set at a minimum extension. It was noted that the amount of the extensions of jack base and u-head affected the specimens' ultimate loads due to stiffness provided by these components $[8,22]$. The effects of the extensions on the ultimate loads were not included in the study. The leveling of beams used to transfer the load from hydraulic jack to scaffold columns was checked prior to load application. The applied load and vertical displacement during load test were monitored by using a load cell and a linear variable displacement transducer (LVDT) as shown in Fig. 4. Eight strain gages were affixed at $50 \mathrm{~mm}$ from the tops of columns at each story level to measure the distribution of axial force in each column during the load test. The columns on each story level were numbered in the clockwise direction. Columns 1 to 4 were at the first level. Columns 5 to 8 were at the second level.

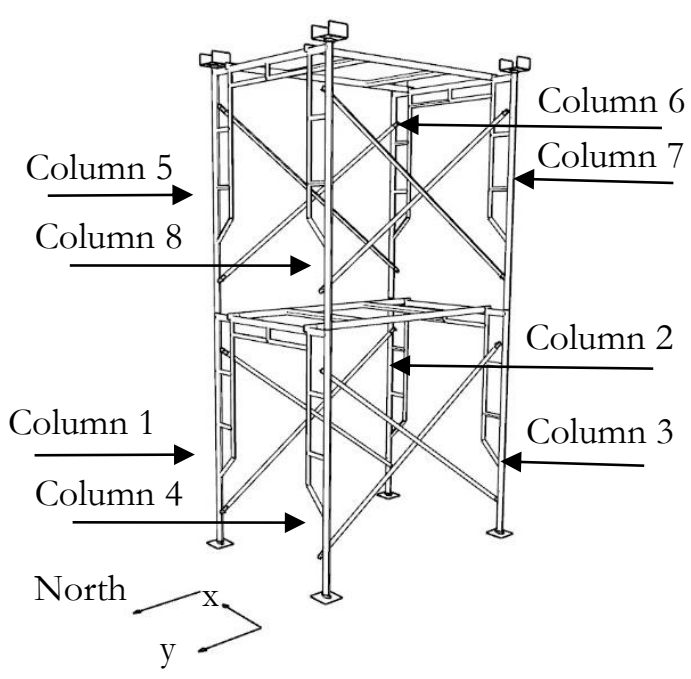

a) Column No.

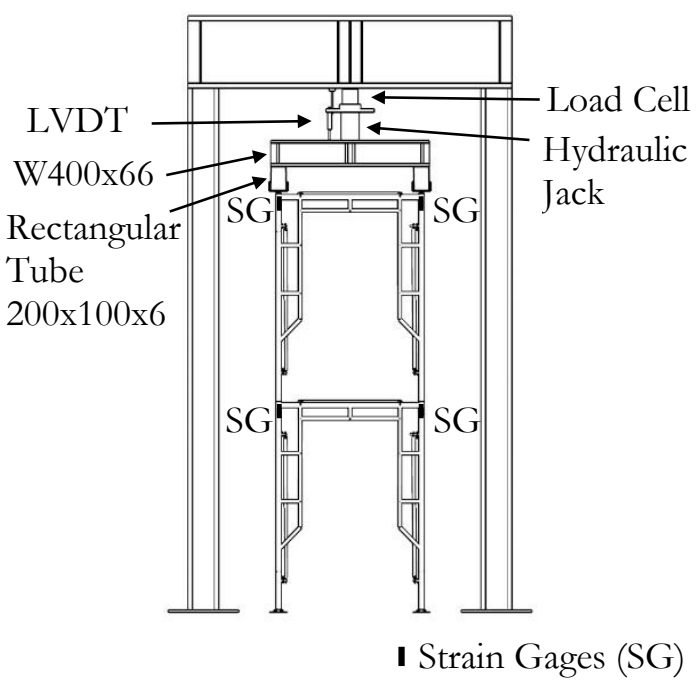

b) Instrumentation

Fig. 4. Experimental setup.

\section{Relationship between Load and Displacement}

Figure 5 shows the relationship between load and vertical displacement of the specimens from initial loading until failure. The specimens exhibited a linear load and displacement relationship to the load level close to the ultimate load. The slope of the load-displacement plot slightly decreased while approaching the ultimate load. This indicated the non-ductile failure behavior of the specimens. The test results of specimens with different levels of initial geometrical imperfections are listed in Table 3. Figure 6 shows the variation and 
mean value of the ultimate loads obtained from the specimens with different initial geometrical imperfections. The average ultimate load of specimens D0 decreased from $182.0 \mathrm{kN}$ in one-story specimens to $155.1 \mathrm{kN}$ in two-story specimens and corresponded to a $14.8 \%$ reduction. This is attributed to flexibility at the joints between lower and upper columns and higher out-of-plumbness in the two-story specimens. The average ultimate loads in specimens S2D1 and S2D2 corresponded to $147.5 \mathrm{kN}$ and $144.0 \mathrm{kN}$, respectively, and corresponding to a reduction of $18.9 \%$ and $20.9 \%$ from one-story specimens. The increases on the reduction of the ultimate loads corresponded to a greater imperfections in these specimens. When compared with specimens S2D0, the average maximum ultimate loads in S2D1 and S2D2 were observed to decrease by 4.9\% and $7.1 \%$, respectively.

The secant stiffness was determined from the slope of the load-displacement curve between the initial loading and $50 \%$ of the ultimate load. The linear relationship between load and displacement was still observed in the region. The average stiffness of $14.1 \mathrm{kN} / \mathrm{mm}$ in one-story specimens decreased to 10.5 $\mathrm{kN} / \mathrm{mm}, 10.3 \mathrm{kN} / \mathrm{mm}$, and $9.6 \mathrm{kN} / \mathrm{mm}$ in specimens S2D0, S2D1, and S2D2, respectively. This corresponded to a reduction in the stiffness by $25.3 \%, 27.0 \%$, and $31.9 \%$, respectively. The significant reduction in stiffness was obtained when the number of stories was increased from 1 to 2 . An increase in the initial geometrical imperfections caused a slight decrease in the stiffness. Significant differential vertical displacement could be obtained from two adjacent scaffolds with a different number of stories and resulted in a variation in the load distribution between scaffolds in the scaffolding system. The scaffold with higher stiffness tends to be subjected to higher load in a system under a uniformly applied load.

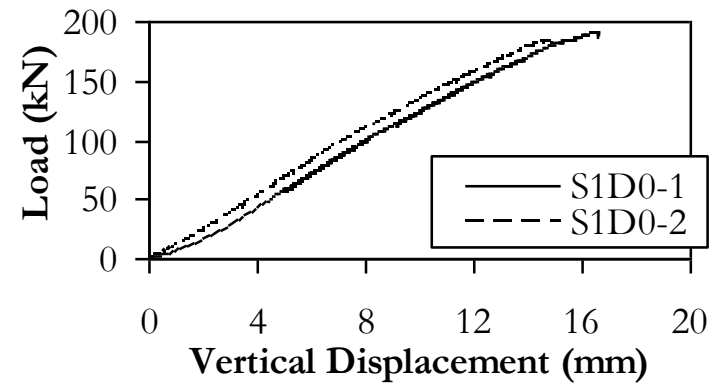

a) S1D0

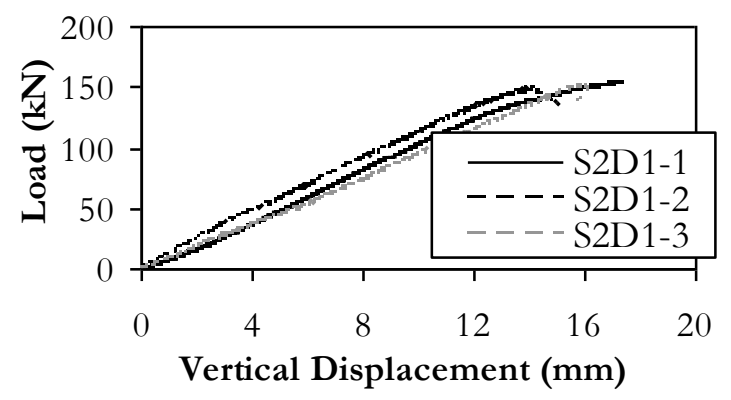

c) S2D1

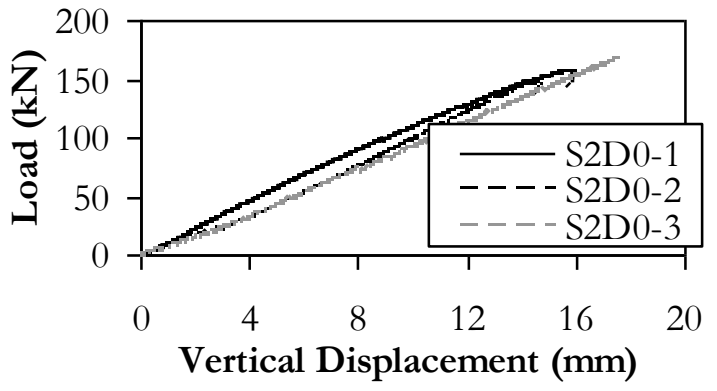

b) S2D0

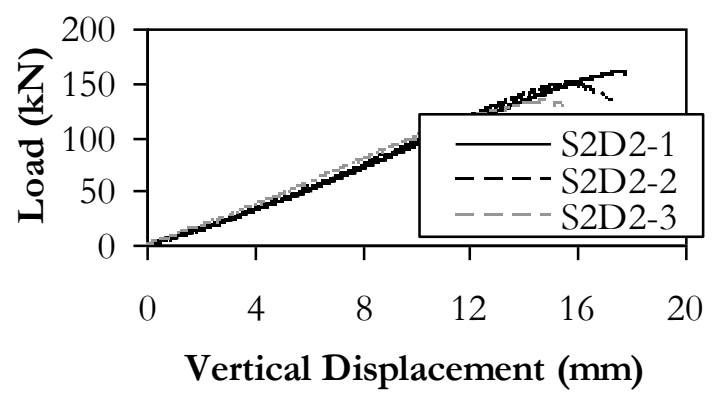

d) S2D2

Fig. 5. Relationship between the load and displacement for different levels of initial geometrical imperfections. 


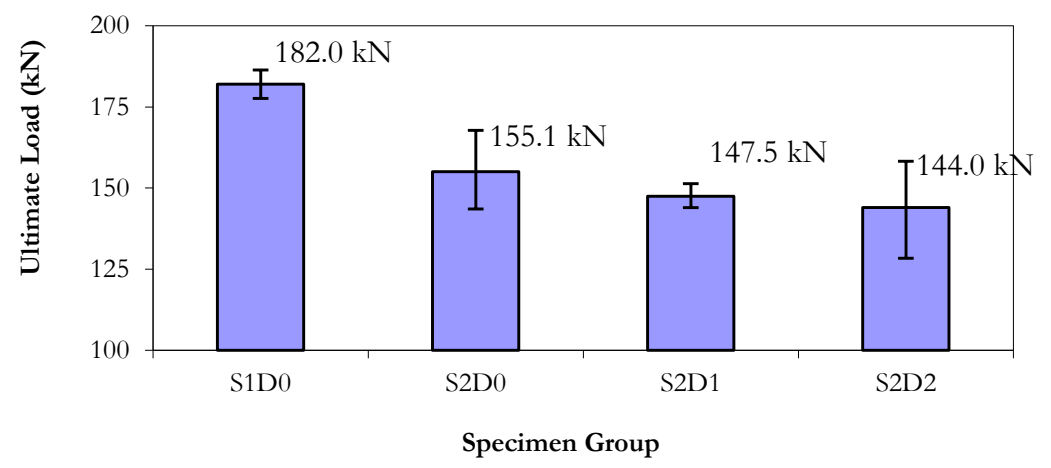

Fig. 6. Average ultimate loads of scaffolds with different levels of initial geometrical imperfections.

Table 3. Experimental results.

\begin{tabular}{|c|c|c|c|c|c|c|}
\hline $\begin{array}{l}\text { Specimen } \\
\text { No. }\end{array}$ & $\begin{array}{l}\text { Ultimate } \\
\text { Load }(k N)\end{array}$ & $\begin{array}{l}\text { Displacement } \\
\text { at Ultimate } \\
\text { Load (mm) }\end{array}$ & $\begin{array}{l}\text { Secant } \\
\text { Stiffness } \\
(\mathrm{kN} / \mathrm{mm}) \\
\end{array}$ & $\begin{array}{l}\text { Mode of } \\
\text { Failure }\end{array}$ & $\begin{array}{l}\text { Failed } \\
\text { Column No. }\end{array}$ & $\begin{array}{l}\text { Buckling } \\
\text { Direction }\end{array}$ \\
\hline S1D0-1 & 186.4 & 16.5 & 14.0 & B1 & 4 & $-Y$ \\
\hline S1D0-2 & 177.6 & 14.8 & 14.2 & B1 & 3 & $-Y$ \\
\hline S2D0-1 & 153.9 & 15.7 & 11.3 & B1 & 7 & $-Y$ \\
\hline $\mathrm{S} 2 \mathrm{D} 0-2$ & 143.5 & 14.6 & 10.7 & M1 & 8 & $-Y$ \\
\hline $\mathrm{S} 2 \mathrm{D} 0-3$ & 167.8 & 18.5 & 9.6 & B2 & $1,2,5,6$ & $-Y$ \\
\hline S2D1-1 & 151.3 & 17.6 & 10.6 & B1 & 6 & $+X$ \\
\hline S2D1-2 & 144.0 & 14.0 & 11.1 & M1 & 5 & $-Y$ \\
\hline S2D1-3 & 147.2 & 15.9 & 9.1 & M2 & 3,7 & $+\mathrm{Y}$ \\
\hline S2D2-1 & 158.3 & 17.6 & 9.4 & B1 & 7 & $+\mathrm{Y}$ \\
\hline S2D2-2 & 145.3 & 15.7 & 9.7 & M1 & 6 & $+\mathrm{Y}$ \\
\hline S2D2-3 & 128.4 & 14.9 & 9.7 & B1 & 6 & $-\mathrm{Y}$ \\
\hline
\end{tabular}

Note: B1 = Sudden failure with the column deformed in single curvature, B2 = Sudden failure with columns deformed in double curvature, M1 = No sudden failure with the column deformed in single curvature, M2 $=$ No sudden failure with columns deformed in double curvature.

\section{Failure Mode}

At the ultimate loads, two failure modes, namely sudden buckling failure and no sudden failure with postpeak strength, were observed. A few specimens abruptly failed due to the buckling of a column member in the scaffolding system and resulted in a rapid decrease in the load carrying capacity of the specimens. This failure mode was observed in one-story specimens (S1D0-1 and S1D0-2) and five of the two-story specimens with different initial geometrical imperfections corresponding to D0, D1, and D2. With respect to the other specimens, a sudden failure was not observed. The specimens could resist a certain amount of the applied load after the ultimate load. After the peak load, the load carrying capacity significantly decreased with increases in the deformation of columns in either diagonal-bracing plane or modular-frame plane. Given a large deformation, the second-order moment due to both out-of-straightness and out-of-plumbness was significant. This failure mode was observed in four of the two-story specimens. Most of the specimens failed with a single curvature shape in one of the columns in the upper story of the scaffolding system. Only specimen S2D1-3 failed in double curvature with a significant deformation of the columns in the upper and lower story levels.

Figure 7 presents the typical failure modes observed in the tested specimens. The summary of failure mode, failed column, and column buckling direction is listed in Table 3. The failure modes with abrupt reduction in the load capacity with single and double curvatures are indicated as B1 and B2, respectively. The 
failure modes with significant second-order moments in single and double curvatures are indicated as M1 and M2, respectively. Most of failed columns were located at the upper story. This was due to the rotational restraint provided by jack base preventing buckling of the lower columns. Additionally, the joint pins used as joints between the lower and upper columns allowed relative rotation between the columns. Most of the specimens buckled in the plane of diagonal bracing in either the $+\mathrm{Y}$ or $-\mathrm{Y}$ directions. Only specimen S2D11 failed in the plane of the modular frame in the $+\mathrm{X}$ direction. This indicated that the investigated door-type modular scaffolds were highly susceptible to instability in the plane of diagonal bracing.

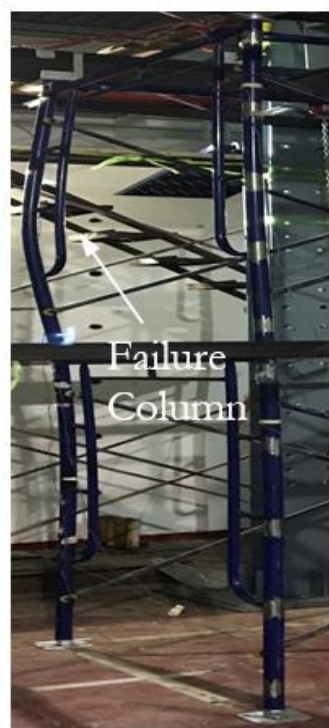

a) Single-Curvature Buckling (specimen S2D0-1)

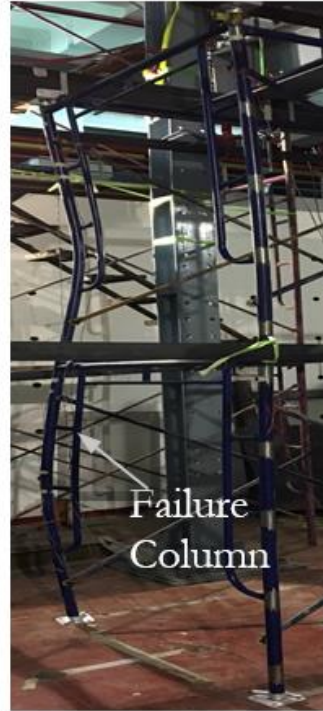

b) Double-Curvature Buckling (specimen S2D1-3)

Fig. 7. Failure mode of specimens.

\section{Load Distribution}

The load distribution between columns in the specimens was determined by using the strain gage readings attached on each column. Figure 8 shows a typical distribution of axial loads among columns in the scaffolding system from zero load up to failure. A linear relationship between axial load and vertical displacement was initially observed at the low load level. When the applied load increased, the relationship between axial load and vertical displacement became nonlinear with significant reductions in stiffness of failure columns prior to the ultimate load.

The failure columns exhibited a reduction in stiffness, and the other columns in the scaffolding system resisted a higher axial load. This was observed from an increase in the slope of load-displacement plot. With respect to specimen S2D0-2, the reduction in the axial load in column 8 resulted in an increase in the axial load in column 7. The axial load was distributed in the plane of cross bracing in the specimen. A similar load redistribution behavior was observed in specimen S2D1-2 but the stiffness reduction occurred at a lower percentage of the ultimate load. 


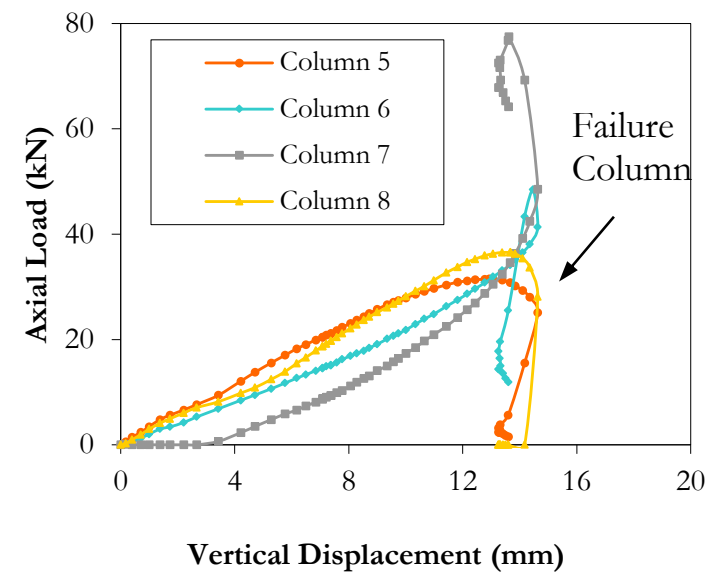

a) S2D0-2

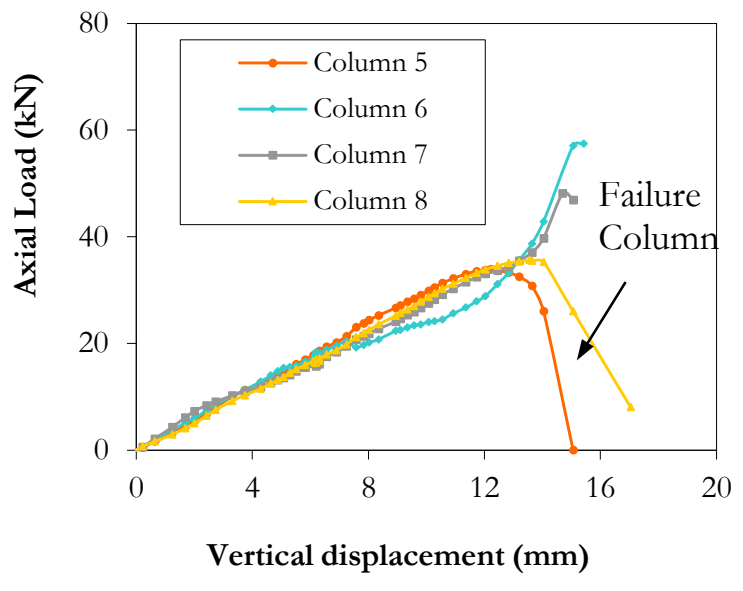

b) S2D1-2

Fig. 8. Load distribution in the columns.

The reductions in the stiffness of the failure column of specimens S1D0 and S2D0 were observed at the load level in the range of $84.9 \%$ to $85.9 \%$ and $79.9 \%$ to $84.7 \%$ of the specimens' ultimate loads, respectively. This indicated that the redistribution of axial loads among the columns initiated at the load level well below the ultimate load although sudden failure was observed in the specimens. With respect to relatively straight columns, the load redistribution in two-story scaffolds (S2D0) occurred at approximately the same percentage of the ultimate load as that in the one-story specimens (S1D0). With increases in the initial geometrical imperfections, the load levels with a significant reduction in the stiffness of the failure column decreased to $74.2 \%$ to $75.6 \%$ and $60.5 \%$ to $68.8 \%$ of the specimens' ultimate loads, for specimens S2D1 and S2D2, respectively.

\section{Utilization and Effective Length}

A strength utilization ratio was employed to assess the structural efficiency of door-type modular scaffolds with different levels of initial geometrical imperfections. It is defined as a ratio between the compressive buckling strength $\left(\mathrm{P}_{\mathrm{c}}\right)$ and the column yield strength $\left(\mathrm{P}_{\mathrm{y}}\right)$ and is expressed as follows [8]:

$$
\chi=\frac{\mathrm{P}_{\mathrm{c}}}{\mathrm{P}_{\mathrm{y}}}
$$

The strength utilization ratio is generally in a range of 0.30 to 0.50 for modular steel scaffolds [8]. The compressive buckling strength of each specimen was determined by using average axial force per column divided by the average column area in each specimen. The average axial force was computed using the ultimate load measured from a load cell. The average yield strength of $435 \mathrm{MPa}$ obtained from the tensile test was used in the calculation. The utilization ratios of specimens with different initial geometrical imperfections are listed in Table 4. The utilization ratios of one-story specimens were in the range of 0.45 to 0.47 with an average of 0.46 . When the number of stories increased from 1 to 2 , the average utilization ratio decreased from 0.46 to 0.40 . With an increase in the initial geometrical imperfections, the average utilization ratios of specimens S2D1 and S2D2 corresponded to 0.38 and 0.37 , respectively. These were slightly lower than that of specimens S2D0.

The design of scaffold generally follows the steel design standard. The ultimate loads corresponding to AISC 360 [23] and BS 5950 [12] were computed. According to AISC 360, the critical stress ( $\mathrm{F}_{\mathrm{cr}}$ of compression member was determined as follows:

$$
\mathrm{F}_{\mathrm{cr}}=\left(0.658^{\mathrm{F}_{\mathrm{y}} / \mathrm{F}_{\mathrm{e}}}\right) \mathrm{F}_{\mathrm{y}} \quad \text { for } \frac{\mathrm{KL}}{\mathrm{r}} \leq 4.71 \sqrt{\frac{\mathrm{E}}{\mathrm{F}_{\mathrm{y}}}}
$$




$$
\mathrm{F}_{\mathrm{cr}}=0.877 \mathrm{~F}_{\mathrm{e}} \quad \text { for } \frac{\mathrm{KL}}{\mathrm{r}}>4.71 \sqrt{\frac{\mathrm{E}}{\mathrm{F}_{\mathrm{y}}}}
$$

Here, $\mathrm{F}_{\mathrm{y}}$ denotes the yield strength, $\mathrm{F}_{\mathrm{e}}$ denotes the elastic buckling stress, $\mathrm{E}$ denotes the modulus of elasticity, $\mathrm{L}$ denotes the laterally unbraced length of the member equal to $1260 \mathrm{~mm}$ for one-story and two-story specimens (Fig. 1a), r denotes the radius of gyration, and $\mathrm{K}$ denotes the effective length factor. The effective length factor is used to multiply an actual column length with various end-restrained conditions to obtain the length of an equivalent pin-ended column. The effective length factor can be determined from the alignment chart. With respect to the braced frame, the effective length factor displays a value less than or equal to 1.0.

The elastic buckling stress $\left(\mathrm{F}_{\mathrm{e}}\right)$ was obtained as follows:

$$
\mathrm{F}_{\mathrm{e}}=\frac{\pi^{2} \mathrm{E}}{(\mathrm{KL} / \mathrm{r})^{2}}
$$

The critical stress $\left(\mathrm{F}_{\mathrm{cr}}\right)$ was determined from BS 5950 by using Perry-Robertson interaction formula as follows:

$$
\begin{gathered}
\mathrm{F}_{\mathrm{cr}}=\frac{\mathrm{F}_{\mathrm{e}} \mathrm{F}_{\mathrm{y}}}{\phi+\left(\phi^{2}-\mathrm{F}_{\mathrm{e}} \mathrm{F}_{\mathrm{y}}\right)^{1 / 2}} \\
\phi=\frac{\mathrm{F}_{\mathrm{y}}+(\eta+1) \mathrm{F}_{\mathrm{e}}}{2}
\end{gathered}
$$

Here, $\eta$ denotes the Perry factor equal to $0.001 \mathrm{a}\left(\lambda-\lambda_{\circ}\right)$, a denotes the Robertson constant equal to 2.0 for cold-formed steel tubes, $\lambda$ denotes the slenderness equal to $\frac{\mathrm{KL}}{\mathrm{r}}$, and $\lambda_{\mathrm{o}}$ denotes the limiting slenderness and is equal to $0.2 \pi \sqrt{\frac{\mathrm{E}}{\mathrm{F}_{\mathrm{y}}}}$.

The critical stresses provided by AISC 360 and BS 5950 were used to estimate the ultimate load of the specimens. The effective length factor $(\mathrm{K})$ of 1.0 was used for pin-ended column. The critical stresses were multiplied with average sectional area of each specimen to obtain the estimated column critical loads. Additionally, the Euler's buckling loads were computed from the elastic buckling stresses. Figure 9 shows the comparison of the column critical loads obtained from the experiment and calculations. Both AISC and BS formulae provided relatively similar values of the critical loads and lower than the Euler's buckling loads. The formulae slightly overestimated of the critical loads for one-story specimens with an average ratio between the AISC and experimental ultimate loads of 1.10. However, the formulae significantly overestimated the critical loads of two-story specimens. The average ratio between the AISC and experimental critical loads corresponded to $1.31,1.37$, and 1.38 for specimens S2D0, S2D1, and S2D2, respectively. This indicated that the AISC formulae with an effective length factor of 1.0 for the braced frame overestimated the critical loads of the two-story specimens.

The effective length factors to provide an accurate estimate of the column critical load from the AISC formula were calculated and are listed in Table 4. The effective length factor of the specimens D0 increased from the average value of 1.07 to 1.17 when the number of stories increased from 1 to 2 . The average effective length factor in the two-story specimens increased to 1.20 and 1.21 for specimens S2D1 and S2D2, respectively. 
Table 4. Effective length factor and strength utilization ratio.

\begin{tabular}{lllll}
\hline Specimen No. & K AISC & Ave. K AISC & Utilization Ratio & Ave. Utilization Ratio \\
\hline S1D0-1 & 1.05 & 1.07 & 0.47 & 0.46 \\
S1D0-2 & 1.08 & & 0.45 & \\
S2D0-1 & 1.18 & & 0.39 & 0.40 \\
S2D0-2 & 1.21 & 1.17 & 0.37 & \\
S2D0-3 & 1.11 & & 0.43 & \\
S2D1-1 & 1.18 & & 0.39 & 0.38 \\
S2D1-2 & 1.21 & 1.20 & 0.36 & \\
S2D1-3 & 1.19 & & 0.38 & \multirow{2}{*}{0.37} \\
S2D2-1 & 1.16 & & 0.40 & \\
S2D2-2 & 1.21 & 1.21 & 0.37 & \\
S2D2-3 & 1.25 & & 0.34 & \\
\hline
\end{tabular}

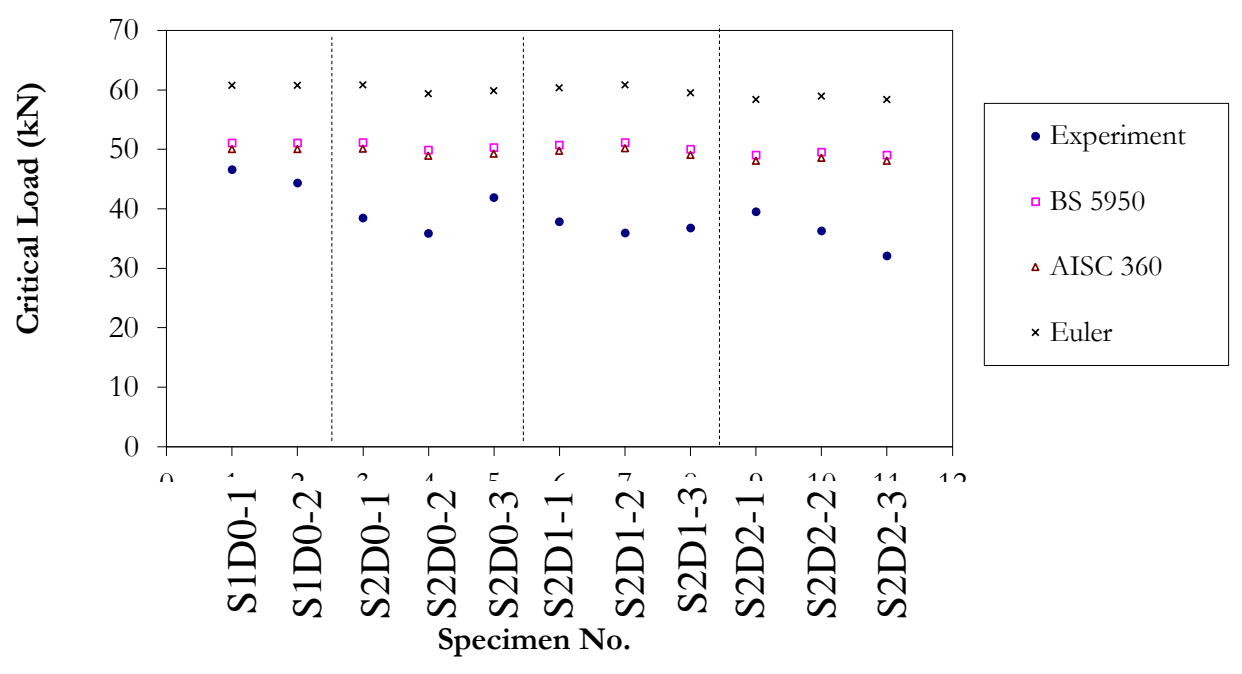

Fig. 9. Comparison between calculated and experimental column critical loads.

\section{Analytical Model}

Finite element analyses were utilized to investigate the structural behaviors and performance of door-type modular scaffolds with different levels of initial geometrical imperfections and boundary conditions. The analytical models were developed by using commercial structural analysis software SAP 2000 [24]. Threedimensional linear buckling analysis was conducted. Due to relatively low stress levels in the columns at failure, the analytical approach could be used to provide a reasonable estimate of the ultimate loads [7,9]. Beam elements with six degrees of freedom per node were employed for all the members. The measured initial geometries and members' dimensions were incorporated in the models. The u-heads and jack bases were excluded in the finite-element models. The end moments of diagonal bracings and ledgers were released to represent the actual behavior of the specimens.

Three different boundary conditions and two continuity conditions between story levels were investigated in the study. The boundary conditions included pinned-pinned (PP) end, pinned-free (PF) end, and partially-restrained (PR) end. With respect to the PP end, the pinned-end condition was assigned at both base and top levels. This boundary condition was employed to represent the simplified boundary condition that is typically used to determine the performance of scaffolds. The PF end with pinned-end at the base level and free-end at the top level was used to evaluate the effect of translation at the top level on the structural performance. With respect to the PR end, the rotational springs were assigned at the base to represent restraint provided by jack bases, and the translation springs were provided at the top level to represent the 
fixity given by the experimental setup. The rotational springs and the translation springs were assigned in both the $\mathrm{X}$ and $\mathrm{Y}$ directions.

The two continuity conditions investigated in the study included fully continuity (FC) and partially continuity (PC) connections between the lower and upper columns. A rigid joint between lower and upper columns was used in the FC connection while flexural fixity between lower and upper columns was partially released in the PC connection. The later was used to allow single curvature failure mode from the analytical models, corresponding to the failure mode observed in most of the tested specimens.

A total of four modeling conditions were employed, including the PP end with FC connection, PF end with FC connection, PR end with FC connection, and PR with PC connection. With respect to the models with PR end with PC connection, the values of spring stiffness and partial fixity were obtained by calibration with the experimental results and were employed for all specimens with different initial geometrical imperfections. The translation spring of $0.76 \mathrm{kN} / \mathrm{mm}$, rotational spring of $7,188 \mathrm{kN}-\mathrm{mm} / \mathrm{rad}$, and partial fixity of $3-10 \%$ with an average value of $5.45 \%$ were used in the study.

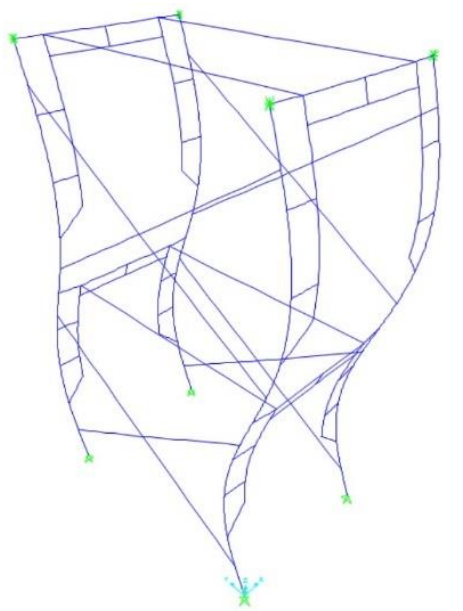

Mode 1: $150.8 \mathrm{kN}$

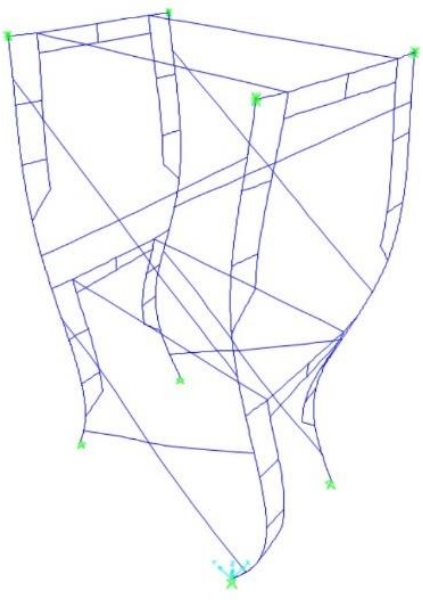

Mode 2: $198.1 \mathrm{kN}$

a) Pinned-Pinned End with Fully Continuity Connection between Columns

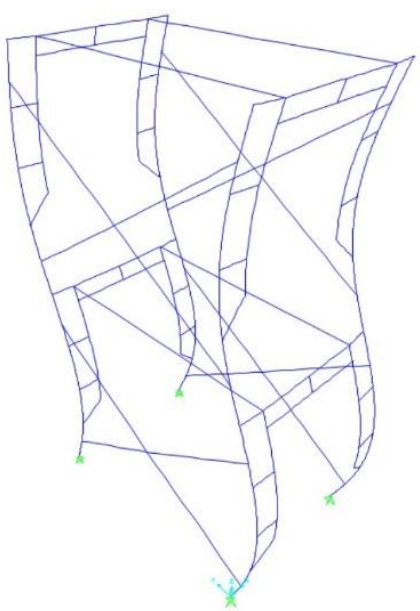

Mode 1: $150.5 \mathrm{kN}$

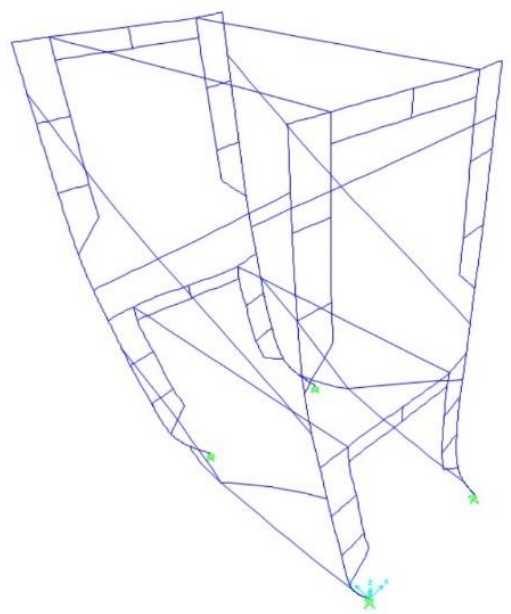

Mode 2: $180.9 \mathrm{kN}$

b) Pinned-Free End with Fully Continuity Connection between Columns 


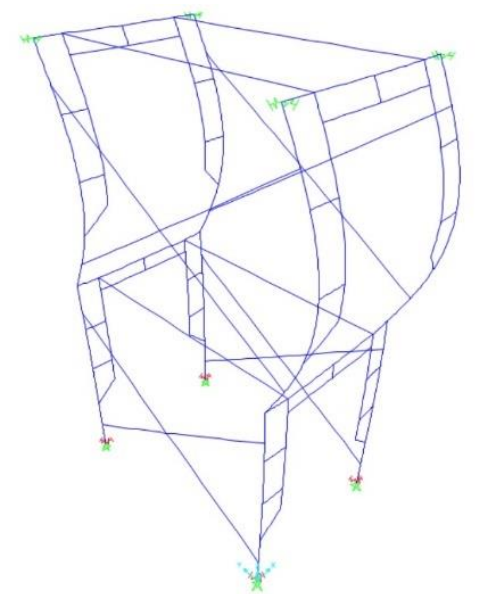

Mode 1: $150.0 \mathrm{kN}$

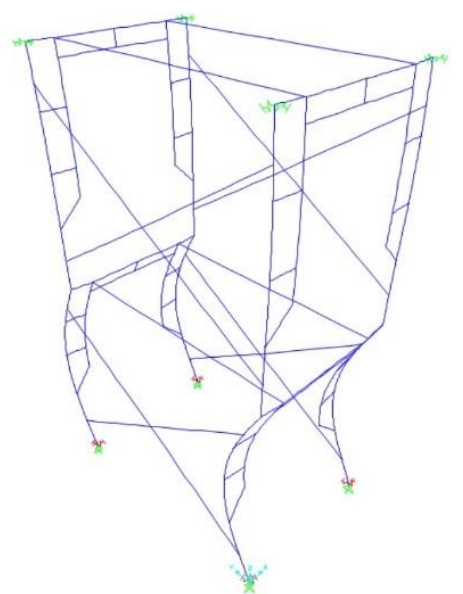

Mode 2: $179.7 \mathrm{kN}$

c) Partially Restrained End with Partially Continuity Connection between Columns

Fig. 10. Fundamental mode shapes and critical loads of specimen S2D0-2 with different boundary and continuity conditions.

Figure 10 presents the typical fundamental mode shapes obtained from different modeling conditions. The mode shape and critical load presented in the figure were the deformed shape and the elastic buckling loads, respectively. The primary failure mode of all modeling conditions was controlled by the failure in the plane of diagonal bracing. The failure in the plane of modular frame was obtained in the secondary failure mode of PF end. In spite of the unbraced condition on the modular-frame plane, the primary failure mode occurred in the plane of cross bracing. This was because the beam linked between columns and sub-frame elements on the door-type modular frame increased the critical stress in this plane. By varying the size of beam element in the models of the specimens with different levels of initial imperfections, the primary failure mode in the modular-frame plane was obtained from the models with PP and PF ends when the outside diameters of the beam linked between columns was assumed to decrease by $61.1 \%$ to $63.7 \%$ and $25.6 \%$ to $29.1 \%$, respectively.

Both PP and PF ends with FC connection exhibited a failure mode of columns in double curvature. The single-curvature failure mode that was similarly observed in the experiment was obtained in the model with partial continuity (PC) connection. Therefore, the fundamental mode shape was significantly affected by the moment of inertia of the beam and sub-frame elements and the continuity condition between story levels.

A comparison of the analytical and experimental ultimate loads is shown in Fig. 11. Both PP and PF ends exhibited a relatively similar value of the critical loads for the specimens with different number of stories and initial geometrical imperfections. This was due to the primary failure mode controlled by the buckling in the plane of cross bracing. The translation at the top level insignificantly affected the ultimate load. With respect to the one-story specimens, the PP and PF ends underestimated the ultimate loads by 14.9 to $18.5 \%$ and 18.7 to $19.0 \%$, respectively. A relatively accurate estimate of the ultimate load in one-story specimens was obtained from the PR end with the rotational spring at the base. The rotational stiffness at the base significantly affected the ultimate load of one-story specimens.

When the rotational spring was assigned at the base, the model with PR end with the FC connection significantly overestimated the ultimate loads of the two-story specimens. This is because the flexibility at column connections decreased the influence of the rotational spring on the ultimate load. Nevertheless, the model with PR end and PC connection provided reasonable estimates of the failure mode and experimental ultimate loads for all two-story specimens with different initial geometrical imperfections. The model provided an error on the predicted ultimate loads in a range of $-4.5 \%$ to $4.5 \%$.

The rotational spring stiffness at the base insignificantly affected the ultimate load of the two-story specimens. Hence, for purposes of simplicity, the pinned-pinned (PP) end with fully-released flexural fixity between columns could be employed. The model yielded an error in the predicted ultimate loads of the twostory specimens in the range of $-8.5 \%$ to $2.5 \%$. 


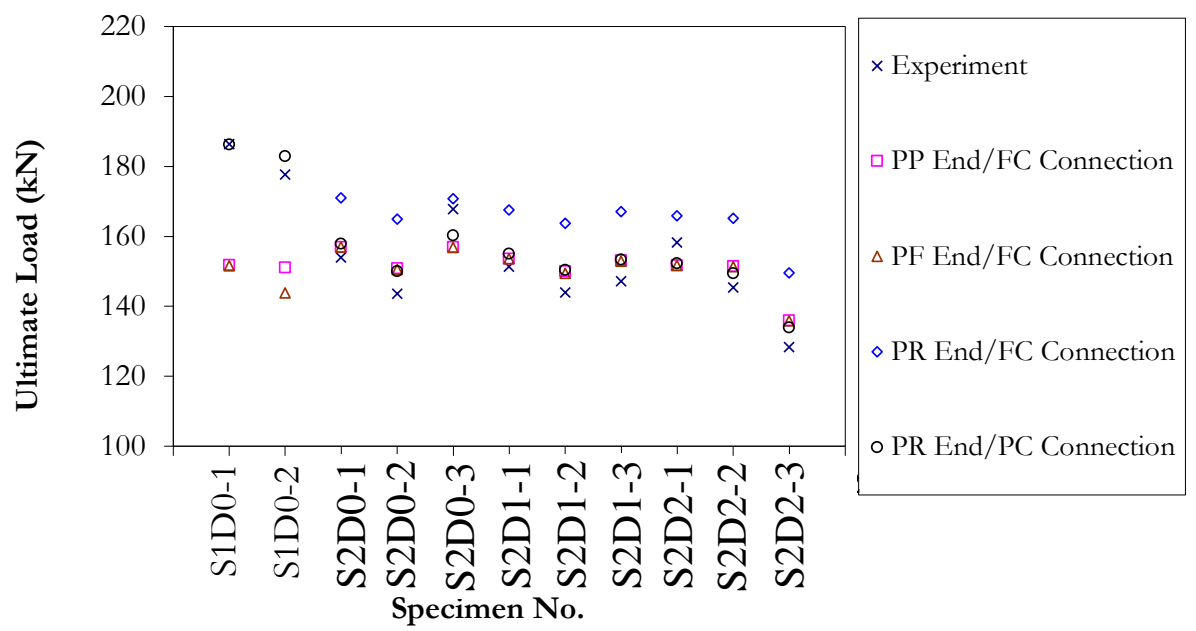

Fig. 11. Comparison of analytical and experimental ultimate loads.

\section{Conclusion}

In this study, the structural behaviors and performances of door-type modular steel scaffolds with different initial geometrical imperfections were evaluated by performing full-scale load tests and analytical investigations. The influences of initial geometrical imperfections and boundary conditions on the load capacity of the scaffolds were evaluated. Based on experimental and analytical results, the following conclusions are obtained:

1. The two-story door-type modular scaffolds with relatively perfectly straight columns had the ultimate capacity of $85.2 \%$ of that of one-story scaffolds. With respect to the out-of-plumbness ratio in a range of $\mathrm{H} / 149$ to $\mathrm{H} / 119$, the average capacity reductions increased to $18.9 \%$ and $20.9 \%$ when the out-of-straightness approached and exceeded the limit specified in the standards.

2. The redistribution of axial load among columns in the scaffolding system and reduction in the stiffness of failure columns occurred at a level well below the ultimate load. A higher degree of initial geometrical imperfections resulted in the initiation of load redistribution and stiffness reduction at the lower load value. This could be used as a monitoring indicator to prevent catastrophic failure of the scaffolds.

3. The critical load obtained from the AISC and BS standards with an effective length factor equal to 1.0 slightly overestimated the ultimate loads of the one-story specimens. The effective length factors in the two-story scaffolds exceeded 1.0 and increased with the degree of initial geometrical imperfections.

4. The beam linked between columns and sub-frame elements increased the critical load in the plane of the modular frame. The primary mode of failure occurred in the plane of cross bracing. With respect to the scaffolds investigated in the study, the initial imperfections on the cross-bracing plane were more critical than those of the modular-plane frame and require closer attention when they are used in construction.

5. The ultimate load of the one-story specimens was significantly affected by the rotational stiffness provided by jack bases. However, the rotational stiffness insignificantly affected the bucking load of twostory specimens due to the rotational flexibility of column joints. With the presence of cross bracing and relatively stiff beam and sub-frame elements, the translational stiffness at the top level had an insignificant effect on the computed buckling load. The rotational flexibility at the connections between lower and upper columns should be included in the analysis to obtain reasonable estimates of the failure mode and ultimate load.

The findings in the study contribute towards a better understanding of the structural behavior of reusable door-type modular steel scaffolds. They provide information that benefits the design considerations and performance of the scaffolds with various degrees of initial geometrical imperfections. 


\section{Acknowledgement}

This study was financially supported by the Department of Public Works and Town \& Country Planning and the Faculty of Engineering, Kasetsart University. The support of Mr. Kiangkai Sathitwiangthong, Mr. Thanaboon Chowthanapanich, Mr. Chutiwat Poolasilapa is also gratefully acknowledged.

\section{Reference}

[1] F. C. Hadipriono H. K. Wang, "Causes of falsework collapes during construction," Structural Safety, vol. 4, no. 3, pp. 179-195, 1987.

[2] J. André, R. G. Beale, and A. M. Baptista, "A survey of failures of bridge falsework systems since 1970," Proceedings of the Institution of Civil Engineers-Forensic Engineering, vol. 165, no. 4, pp. 161-172, 2012.

[3] R. G. Beale, "Scaffold research-A review," Journal of Constructional Steel Research, vol. 98, pp. 188-200, 2014.

[4] W. K. Yu, K. F. Chung, and S. L. Chan, "Initial geometrical imperfections in three-storey modular steel scaffolds," Seventeenth International Specialty Conference on Cold-Formed Steel Structures, Orlando, Florida, U.S.A., November 2004.

[5] H. Zhang, T. Chandrangsu, and K. J. R. Rasmussen, "Probabilistic study of the strength of steel scaffold systems," Structural Safety, vol. 32, no. 6, pp. 393-401, 2010.

[6] S. L. Chan, Z. H. Zhou, W. F. Chen, J. L. Peng, and A. D. Pan, "Stability analysis of semirigid steel scaffolding," Engineering Structures, vol. 17, no. 8, pp. 568-574, 1995.

[7] L. B. Weesner and H. L. Jones, "Experimental and analytical capacity of frame scaffolding," Engineering Structures, vol. 23, no. 6, pp. 592-599, 2001.

[8] W. K. Yu, K. F. Chung, and S. L. Chan, "Structural instability of multi-storey door-type modular steel scaffolds," Engineering Structures, vol. 26, no. 7, pp. 867-881, 2004.

[9] G. P. Cimellaro and M. Domaneschi, "Stability analysis of different types of steel scaffolds," Engineering Structures, vol. 152, pp. 535-548, 2017.

[10] J. L. Peng, A. D. E. Pan, W. F. Chen, T. Yen, and S. L. Chan, "Structural modeling and analysis of modular falsework systems," Journal of Structural Engineering, vol. 123, no. 9, pp. 1245-1251, 1997.

[11] J. L. Peng, K. H. Chen, S. L. Chan, and W. T. Chen, "Experimental and analytical studies on steel scaffolds under eccentric loads," Journal of Construction Steel Research, vol. 65, no. 2, pp. 422-435, 2009.

[12] British Standards Institution, "Structural use of steelwork in building. Part 1: Code of practice for design - rolled and welded sections," BS 5950, 2000.

[13] J. L. Peng, C. M. Ho, C. C. Lin, and W. F. Chen, "Load-carrying capacity of single-row steel scaffolds with various setups," Advanced Steel Construction, vol. 11, no. 2, pp. 185-210, 2015.

[14] Standards Australia, "Steel structures," AS 4100-1998 (R2016), 2016.

[15] American Institute of Steel Construction, "Code of standard practice for steel buildings and bridges," ANSI/AISC 303, 2016.

[16] British Standards Institution, "Code of practice for temporary works procedures and the permissible stress design of falsework," BS 5975, 2008.

[17] Canadian Standards Association, "Code of practice for access scaffold," Z797-09 (R2014), 2014.

[18] Occupational Safety and Health Branch Labour Department, "Code of practice for metal scaffolding safety," 2013.

[19] American Society for Testing and Materials, "Standard practice for measuring thickness by manual ultrasonic pulse-echo contact method," ASTM E797/E797M-15, West Conshohocken, PA, 2015.

[20] American Society for Testing and Materials, "Standard test methods for tension testing of metallic materials," ASTM E8/E8M-16a, West Conshohocken, PA, 2016.

[21] E. J. Pavlina and C. J. Van Tyne, "Correlation of yield strength and tensile strength with hardness for steels," Journal of Materials Engineering and Performance, vol. 17, no. 6, pp. 888-893, 2008.

[22] J. Reynolds, H. Zhang, and K. J. R. Rasmussen, "Investigation of u-head rotational stiffness in formwork supporting scaffold systems," Engineering Structures, vol. 136, pp. 1-11, 2017.

[23] American Institute of Steel Construction, "Specification for structural steel buildings," ANSI/AISC 360-16, 2016.

[24] CSI, SAP2000-Linear and Nonlinear Static and Dynamic Analysis and Design of Three-Dimensional Structures. Berkeley, California, USA, Computers and Structures, Inc., 2012. 